\title{
Three-Dimensional Strain Variation across the Kathmandu Nappes: Insight to Nappe Emplacement Mechanism
}

\section{Deepak Chamlagain}

\author{
Department of Environment Science, Amrit Science College, Tribhuvan University, Kathmandu, NEPAL \\ * For correspondence, email: dchamlagain@hotmail.com
}

\section{Introduction}

The Main Central Thrust (Mahabharat Thrust of Stöcklin 1980) is one of the key thrusts in central Nepal Himalaya to understand the nappe tectonics because it is considered that MCT acted as a glide plane for the thrust sheets, which traveled more than $100 \mathrm{~km}$ towards south over the LHS forming a large folded-thrust sheet called Kathmandu Nappe. Much of the research has been focused on structural and kinematic analysis of the MCT zone, a root zone of the Kathmandu Nappe. These studies have confirmed a topto-the south directed sense of shear in the MCT zone, which is associated with the emplacement of Kathmandu Nappe. Although large-scale geometry of the Himalayan thrust sheets and nappes are relatively understood, features of the internal deformation are not well understood in terms of strain geometry. Several studies have shown that the pattern of the internal deformation varies between thrust sheets because it depends on pressure, temperature, and complex tectonic boundary condition. Although strain analysis bears important clues to understand internal deformation, there is still lack of studies across the Himalaya nappes. It is, therefore, necessary to address several problems like (1) three-dimensional strain geometry, (2) relation between inverted metamorphism and strain pattern, (3) precise kinematic model to reveal nature of internal deformation and emplacement mechanism. These issues are certainly useful to decipher tectonics of the Himalayan nappes and thrust sheets. This study, therefore, mainly attempts to discuss above-mentioned issues using structural data, three-dimensional strain geometries, and metamorphism across the MCT and basal part of the Kathmandu Nappe in central Nepal Himalaya (Figure 1).

\section{Structural Geology}

In the study area, the MCT is only a major thrust that served as a glide plane along which Kathmandu Nappe has been emplaced towards south from its root zone. It carried Precambrian to Devonian rocks over the Lesser Himalaya. Although displacement magnitudes are difficult to determine for the MCT, $100 \mathrm{~km}$ was estimated at least (Johnson et al. 2001). The entire thrust sheet has

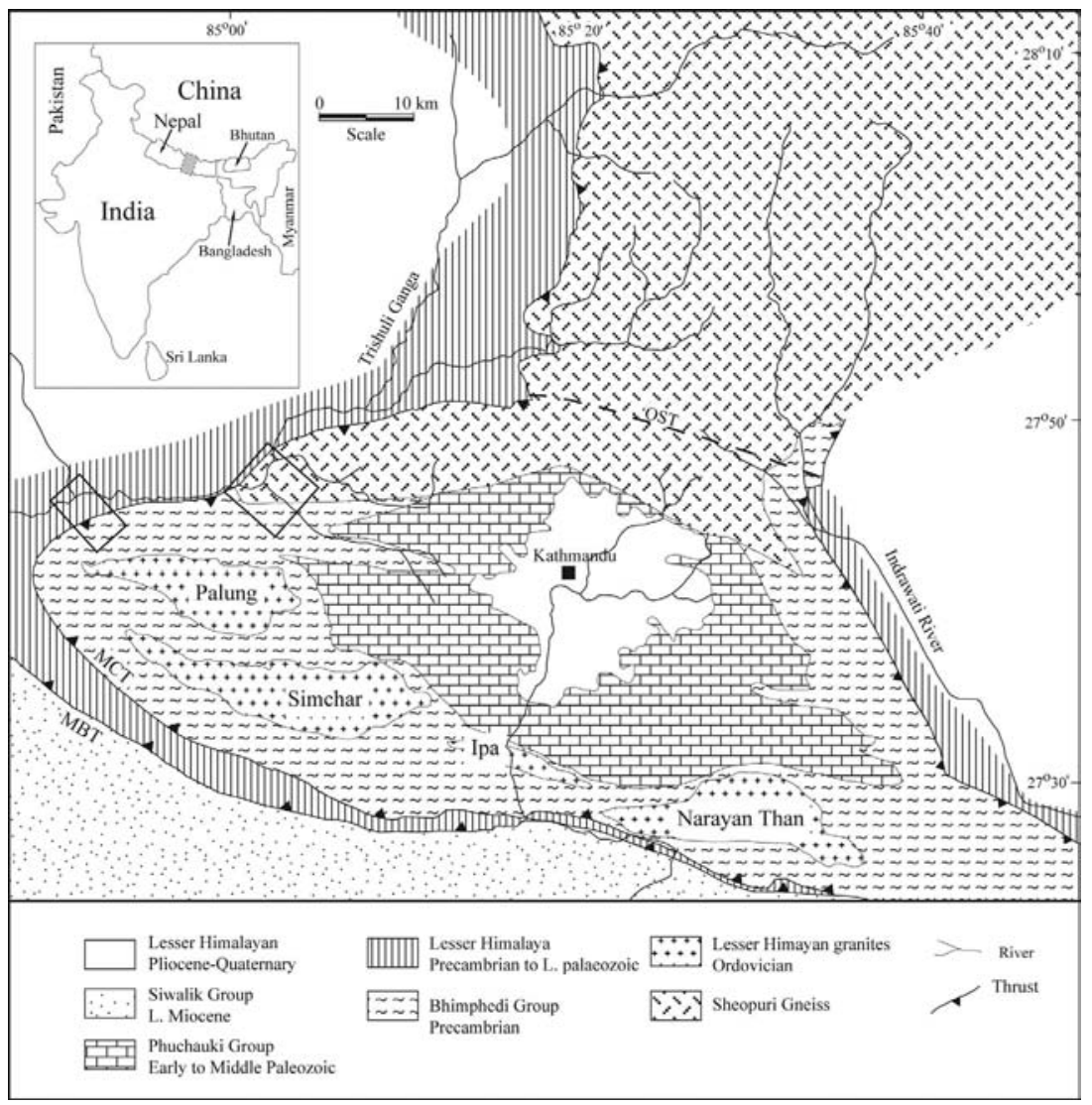

FIGURE 1. Geological map of central Nepal (modified after Stöcklin 1980). MCT: Main Central Thrust, MBT: Main Boundary Thrust, OST: Out of sequence thrust. Rectangles show studied areas. 
an oval shape structure and convex towards the foreland, which is folded giving rise to large synclinorium. Along the Malekhu Khola section, complete sequences of both footwall and hanging wall are well exposed. About $100 \mathrm{~m}$ thick mylonite, and phyllonite zones characterize MT zone, where thrust related structures are abundant. In the study area, the NE-SW trending MCT represents thin ductile zone with the highest degree of finite deformation. It is distinctly marked by a penetrative foliation, and stretching and mineral lineation. Deformation fabric intensities are generally homogeneous at the outcrop scale. Foliation within the quartzites and schists is defined by aligned biotite and muscovite, and the mineral lineation is defined by streaking of mica domain in foliation surfaces in schists and in quartzites by quartz grain-shape alignment. In the footwall, platy phyllites display lineation with south-southwest plunge and the foliation planes in the footwall block show steep dipping towards south. Near to MCT, mylonitic quartzite is characterized by the strong stretching lineation with southwest plunge. The S-C fabrics at the MT zone show top-tothe-south directed shear sense (Johnson et al. 2001). At the central part of thrust zone, quartz veins are often folded asymmetrically and the axial plane is sub-parallel to the foliation plane. Garnet grains of centimeter scale are normally present in the MT zone. At the base of the hanging wall, the garnetiferous schist (Raduwa Formation) is well foliated with poorly developed linear structures. Foliation plane is dominantly dipping towards south excluding area at the proximity of MCT. At least three phases of deformation can be documented: first (D1) development of S1 parallel to So. Second (D2) phase is mostly observed along the Mahesh Khola and is characterized by the tight folds and lineations, which moderately plunge toward southwest. The axial planes of these folds are slightly oblique to the $\mathrm{S} 1$ foliation and, S2, a new schistosity is incipiently developed along the axial plane of the F2 folds. F2 fold is considered as a refolding of the F1 folds. The D3 deformation phase is characterized by the F3 and consists of crenulation cleavages with easterly or southeasterly plunges and steeply dipping axial plane trending east-west or northwest-southeast. The linear structure associated with the D3 deformation is roughly considered parallel to the axis of the Mahabharat synclinorium which trends east southeast. Structural data support a single nappe model considering Mahabharat Thrust as a southern continuation of the MCT, which acted as a glide plane for Kathmandu Nappe.

Three-Dimensional Strain Geometry

Three-dimensional strain data show heterogeneous strain field both in footwall Lesser Himalayan sequence (LHS) and hanging wall (Kathmandu Nappe). In the footwall Nadai amount of strain intensity ( ) varies from 0.396 at the base to 0.575 adjacent to the MCT whereas in the Kathmandu Nappe, it varies from 0.345 to 0.946 . In general, the footwall block shows increasing trend of value towards MCT whereas in the Kathmandu Nappe increases away from the MCT (Figure 2). Lower value of at the base of the Kathmandu Nappe is due to thermal relaxation that led to a low temperature dynamic metamorphism and plastic deformation after the emplacement of hot Kathmandu Nappe. The complex patterns of orientation of the strain ellipsoids are due to superposition of strain partitioning mechanisms on different scales, which have also created a complex regional strain variation in terms of magnitude. The shape, orientation of strain ellipsoids, and mesoscale structural data indicate transpressional strain field in the MCT zone. The dominancy of prolate type strain ellipsoids suggest simple shear model for the footwall LHS. In the hanging wall, however, strain field is dominantly oblate type with few prolate types suggesting pure shear with a thrust parallel shortening model (Figure 2). For the both walls computed kvalues have revealed non-plane strain deformation for the MCT, which is apparently consistent with several fold-and-thrust belts on the earth.

\section{Emplacement Mechanism}

Various models have been designed to explain the exhumation of the HHCS e.g. (a) rigid extrusion (b) ductile channel extrusion or channel flow (c) Ductile extrusion by general shear. None of the models are able to show complete scenario of the exhumation mechanism of the HHCS. Recently, Channel flow model is widely used but also a matter of strong debate. This model for the Himalaya-Tibet orogenic system are particularly intriguing because of the proposed link between channel flow and ductile extrusion driven by focused precipitation/denudation at the Himalayan topographic front (Beaumont et al. 2001). The primary drivers for channel flow in the Himalayan-Tibetan Orogen are (1) unusually weak zones that exist in the crust at different depths throughout
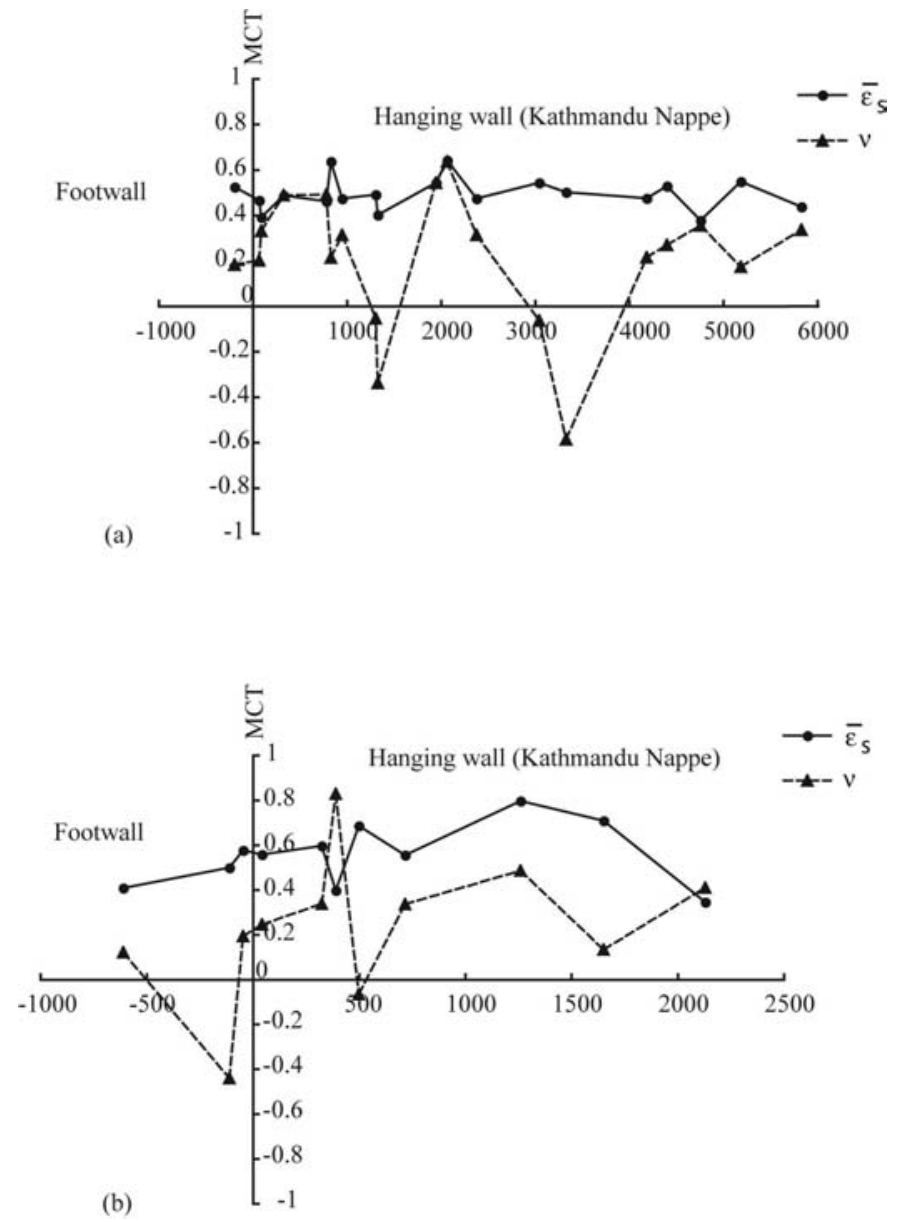

FIGURE 2. Variation of strain parameters across the MCT (a) Galchhi area (b) Malekhu area. Note that measured distance (in meter) is normal to the MCT. 
the modern Tibetan Plateau, and (2) that gravitational/pressuredriven flow. Based upon results from the INDEPTH studies, Nelson et al. (1996) proposed that crust on the leading edge of the subducting Indian plate partially melts below the Lhasa terrane, and flows southward toward the Himalayan orogenic front, where it is denudationally extruded between the coeval MCT and STDS as Higher Himalayan rocks. Harrison (2006) opposed this concept because their 'bright spots' restricted to a single rift and evidence that they represent aqueous fluids rather than molten silicate; the seismogenic nature of Moho in southern Tibetan and $3 \mathrm{He} / 4 \mathrm{He}$ data indicates the presence of mantle heat and mass in the rift valley. Therefore, any melt present is due to late Neogene calc-alkaline magmatism and is supported by the lack of Tertiary migmatites in the crustal section exposed in the uplifted rift flank of the Yangbajain graben. The absence of Gangdese zircon xenocrysts in the Higher Himalayan rocks and the broadly coherent stratigraphy further put question on validity of channel flow model. Further, the model must explain observed geological relationships in the nappes composed of rocks of HHCS. For example in central Nepal the MCT juxtaposes hanging wall rock that consists of the Higher Himalayan rocks (Bhimphedi Group of Stöcklin 1980) against LHS rocks. However, there is no evidence of normal fault equivalent to STDS that serves as an upper bounding fault for the extruding channel. Therefore, the lack of an upper bounding shear zone clearly suggests that existing channel flow models that describe the emplacement of HHCS rocks in the High Himalaya may not apply to the Kathmandu Nappe. Gross stratigraphic relationships within the well-bedded Bhimphedi Group appear to be intact and in the more quartz-rich lithologies, primary sedimentary structures such as cross-beds and ripple marks can be observed (Stöcklin 1980). If rocks of the Bhimphedi Group flowed within a channel, it is highly likely that original stratigraphic relationships and sedimentary structures would have been obscured. Further, central Nepal Himalaya doesn't show the coupling between the climate and tectonics, posing question on validity of the channel flow model. Rather, structural and three-dimensional strain data support the general shear extrusion model proposed by Vannay and Grasemann (2001).

References

Beaumont C, RA Jamieson, MH Nguyen and B Lee. 2001. Himalayan tectonics explained by extrusion of a low-viscosity crustal channel coupled to focused surface denudation. Nature 414: 738-742

Harrison TM. 2006. Did the Himalayan Crystallines extrude partially molten from beneath the Tibetan Plateau? In Law RD, MP Searle and L Godin (eds.) Channel Flow, Ductile Extrusion and Exhumation in Continental Collision Zones. Geological Society, London, Special Publications 268: 237-254

Nelson KD and others. 1996. Partially molten middle crust beneath southern Tibet; synthesis of Project INDEPTH results. Science 274: 1684-1688

Stöcklin J. 1980. Geology of the Nepal and its regional frame. Journal of the Geological Society of London 137: 1-34

Vannay J-C and B Grasemann. 2001. Himalayan inverted metamorphism and syn-convergence extension as a consequence of a general shear extrusion. Geological Magazine 138: 253-276 